Chapter 29

\title{
Adding Value in Food Production
}

\author{
Rebecca Dare, Håkan Jönsson and Hans Knutsson
}

Additional information is available at the end of the chapter

http://dx.doi.org/10.5772/53174

\section{Introduction}

This chapter investigates the practice of value adding in food production, by taking a view from a food manufacturer that has found itself in recent years increasingly integrated into the food industry: small-scale farming Producers. Specifically, their construction and practice of value adding 'authenticity' to food products is revealed.

The objective of this chapter is twofold. One is to study the process of and provide a new perspective on value adding, with an emphasis towards 'authenticity' in food. This examination delivers new knowledge and provides future direction to small scale farming Producers and the wider food industry. The secondary objective is to provide a demonstration to the value of Applied Cultural Analysis in food development.

The practices of small-scale Producers will be explored through an ethnographic approach, combining participant observation and interview. This investigation intend to uncover how and what is value added by small scale Producers: in the values they infuse in their food commodities, of the value found in their way of life, and the value in their production practices. It is an examination of the small, unconscious acts revealed through ethnographic enquiry and the lens of cultural theory to reveal the practice of value adding 'authenticity' as a culturally constructed act. These findings will be demonstrated as important not only for Producers in understanding their practices, but also for the wider food industry concerned with value adding authenticity in their food products

\subsection{Adding value - A problem definition}

First of all we have to establish what value is. When following, in a business context, the enduser of a product or service appreciates its use, he or she values the consumption. In return for the value that the business firm produces, the customer pays for the value. The economic value is determined by the subtraction of cost (effort) from the perceived benefit of using the 
product in question (Peteraf and Barney, 2003). Perceived benefits, then could be anything status, self-confidence, health, satiety, excitement or whatever the user gets from the product.

A simplistic view of adding value to food brings with it straightforward notions of 'adding' to raw ingredients and processing them in a way that increases economic return. A useful supporting definition of this starting view to 'value added' is provided by the United States Department of Commerce and Industry, which outlines any processing of food as a value added act in and of itself:

Processed foods are "value-added" products, referring to the fact that a raw commodity or commodities are transformed into a processed product through use of materials, labour, and technology. Any product that requires some degree of processing is referred to as a processed product, regardless of whether the amount of processing is minor, such as for canned fruit, or more complex, such as for snack foods (2008; p. 3)

However, the processing of food is not as straightforward as gathering materials, labour and technology together equals automatically producing a value added product. In recent years, a increased emphasis on the addition of culture as a value is an evident phenomenon in the food market today that introduces an element of complexity and requires deeper investigation and further definition. Paul DuGay and Friedmann defines the addition of culture as a value that adds the "inscription of meanings and associations as they are produced and circulated in a conscious attempt to generate desire for them amongst end users" (DuGay \& Friedmann, 2002, p. 7).

In close connection to the discussion of culture as value is the commercial value of authenticity in food products. Several large industry consultant groups refer to the importance of value adding, with statements such as:

Key trends to impact the food and beverage market through 2012 and beyond... relate to purity, authenticity and sustainability, as consumers continue to look for products with added value. (Innova Market Insights, 2011)

Added value still matters. Despite lingering economic uncertainty and mounting scrutiny of product health claims, consumers remain willing to spend a bit more on food that does, or stands for, 'something'. (Euromonitor International, 2010)

Value adding could be seen as the reinvention of product for economic gain. But what is the reinvention happening - what are the processes at play? Let's continue with the idea of processing as value adding in food. This processing of a raw commodity to product can also be described as a process of cooking. The french anthropologist Claude Levi-Strauss (1994), wrote in his classical article on the culinary triangle about the processes of cooking and described it as an "...act of mediation, where we transform raw materials into a cooked prod- 
uct... not only does cooking mark the transition from nature to culture, but through it and by means of it, the human state can be defined with all its attributes" (p. 164-5).

Focusing on the words of mediation, transformation and culture, cooking can be viewed as a process to mediate what and how is added in, or transited out; to transform into a final product is a practice to inscribe cultural meaning to the human state. It's the selection of these elements that positions the function of the cook (or food manufacturer) as a mediator at the conjunction of final product to the consumer and therefore places them in the position of cultural agent(s). Culture becomes an important part of the production in cooking - the combination of what cultural meaning and associations are selected and represented in this transformation is the challenge in 'cooking' and thus the 'value add'. Cultural processing and processes bind the selection of chosen elements that can be simplicity, rarity and tradition. Therefore to produce a 'value added' food product, an understanding of cultural processes is required - a complex task in which the food industry finds itself involved.

According to Mintel (2011), an astonishing 20,000 new "value added" products per month are launched in the global food industry. However, a demonstration of the complexity involved with cultural interpretation, and just how challenging creating a cultural product can be, is found in the exceptionally high failure rate, "exceeding 90 per cent for some categories, which suggests that firms have difficulty in developing products that appeal to enough people to warrant continued distribution" (Connor \& Schiek, 1997).

Combined, this has created a food industry both focused on creating new added-value products while at the same time, working to minimise the potential risk of failure and subsequent economic loss. The sheer number of products also hints to the increasing complexity of adding value to products by the inscription of cultural values. These cultural values often take the form of ideologies, experiences, morals, mythology, magic and sometimes illusion infused within the product offer and branding, such as Coca Cola's inscription to transform a carbonated soft drink to the embodiment of the spirit and essence of America, summarised in their advertising plans:

Coke is real, authentic, honest, passionate and refreshing. It taught us to sing in perfect harmony. It even introduced us to Santa Claus. Coke is the kind of cultural fabric that unites all of us in some way. It has always encouraged us to share who we are and what we believe in (Identity Advertising, 2007, p. 2).

The creation of 'value added' inscribed in food is thus an effort to elicit emotion from consumers and entice them to spend more money in return for feeling this emotion. Value adding is a basis for economic gain via emotion, and it is emotion that becomes critical in the evaluation of how successful a value add food product is. It is also one of the more difficult to interpret - one cannot simply walk up to a consumer and ask what their emotions regarding a certain product are - they would not be able to tell you. It leaves mediators (cooks) charged with the responsibility to decode cultural meaning and charge their products with it by their practices. It also leaves the assessment of their labours as ephemeral and complex. It is information that needs to be teased out, tantalisingly revealed and then hidden, uncov- 
ered by other means - lending qualitative research methods such as ethnology and anthropology as critical in the understanding and evaluation of value added food.

For the food industry, the tension created between potential and seemingly boundless creative transformative opportunity available in developing 'new' value added products is balanced against the underlying understanding of risk in both the emotive assessment of the culture that is infused and also in economic terms has led to, as Belasco (1989, p. 210) states, "corporate conservatism", neatly outlining a response from the food industry to address both perceived risks: there has been increased focus to consumer-directed research, in some instances as broadly to elevate its importance into the heart of day to day business operations, while at the same time to reduce the costs in bringing a product to market. The emergence of qualitative research methods to uncover 'insight' in the food industry saw an increasing investment to understanding food consumption within a daily life context when developing value added products. This however, is a difficult task when we consider the unconsciousness of taste and how unaware we can be about the food we eat on a daily basis.

The environment in which we eat our meals also demonstrates the quiet absorption of food into the background of daily life. In a 2011 report, it was suggested that in an average person's day, $56 \%$ of the time spent eating (85 of 152 total minutes) is while engaged in another activity considered primary such as watching television, driving, preparing meals, or working (Hamrick, 2011, p. 5). We're not even paying full attention to over half the food that goes in our mouths, yet significant amounts of time and money are invested by large food manufacturers trying to get consumers to tell them why they eat what they do.

The complexity in dissecting everyday life within business constraints such as timelines / budgets in a climate of conservatism and cost reduction has conceivably led to an avoidance of radically innovative products.

The reduction of economic risk by bringing down costs in value adding is also demonstrated with the use of materials (such as synthetic / non-food additives, flavour enhancers, thickeners, colours, stabilizers), a change in business operations such as off shore manufacturing, combined actions of which have increased the length and complexity of the food chain and the distance - both geographical and mental - between the raw and the cooked. It is this distance created over the past 50 years that's had a hand in creating the demand for authentic products and places small-scale production in the position it finds itself today.

Given the ongoing involvement and importance of value adding authenticity in food by these large companies, it may seem surprising that small-scale food Producers were not run out of the industry long ago. Instead, these Producers find themselves in a strong and growing position within the food market for value added authenticity. For example, direct to consumer sales from small scale farming production have grown 104.7\% from 1997 to 2007 (Martinez, 2010), and 60\% of the Swedish population prefers to buy local produce (Ekelund, Fernqvist \& Tjärnemo, 2007, p. 233). 


\section{Understanding value adding}

\subsection{Food and cultural studies traditions}

There is a long tradition in cultural and sociological food studies regarding the consumption or meaning of food and does provide a basis for understanding a consumer perspective, and how demand is created. Existing food studies credit food consumption for a vast array of cultural process from the reproduction of a stable society (Lupton, 1996; Goody, 1982), the decoder of the unconscious attitudes of a society (Levi Strauss, 1994), of nationality (Barthes, 1967), as an indicator of class (Mennell, Murcott \& van Otterloo, 1992; Bourdieu, 1984), social significance (what is important in a given society) (Douglas, 1982), to the relation of food in feminist studies and body shape (Adams, 1990). Taken together, these studies point to food as central to culture, a suitably broad implication that requires narrowing.

In narrowing to the central theme of this chapter - value adding and authenticity - the central ideas that emerge from a consumer perspective is that consumption of small-scale, authentic food is enjoyed largely by the elite upper classes in westernised societies - the diets of the poor have remained relatively unchanged: they are excluded from this possibility (Bourdieu, 1994). However, Alan Warde (1997) argues that the emphasis is shifting from class formation towards the formation of new groups in society that share 'lifestyle' rather than social class, and the consumption of 'authentic' food is a representation of chosen lifestyle group. A study by Anthony Giddens (1991) takes a wider view, outlining that the agency of consumers is emphasised over both the social and economic structures in which they find themselves, and this is a crucial means of establishing an individual's identity. The emergence of consumption of small-scale authentic food is also evidently associated with the mitigation of food risk and potential for disease as explored by Ulrich Beck (1992) and Mary Douglas (1996, p. 123).

Further, in specific regard to the term of authenticity, a concrete definition is a little difficult to locate. It has been described as a product of shared systems of signification (Ashley et al, 2004, p. 7) and is a modern phenomenon (Appadurai, 1986). What constitutes as 'authentic' changes over time (Peterson, 1997), an example of which is exemplified with the shift in lard heavy foods recipes - such as Cassoulet - where goose fat may be substituted for cheaper and lighter alternative fat sources but still acceptably remains an authentic French dish.

In some cases, authenticity has been deciphered as an act of micro-resistance to dominant forms of cultural production (De Certeau, M; Giard, L \& Mayol. P, 1998) - where one makes an appeal for authenticity in response to their perception of inauthenticity in others. For example, you are what you don't eat. Josée Johnston \& Shydon Baumann (2010, p. 70) provide a key view on authenticity with their claim that it "doesn't really exist" as it is socially constructed. The definitions of authenticity are difficult to define concretely and are deliberately vague in use here, as it is the cultural construction through practice that this thesis aims to reveal.

It's important to note that the term of 'consumer' can be applied to Producers in this chapter, also - after all, as we all are when it comes to food - the small-scale producers in this 
study are consumers, too. There is argument that Producers are developing products they personally consume.

\subsection{A new food economy}

The increasing intertwinement of "culture" and "economy" is a focal point in both cultural studies and economics during recent years (duGay \& Pryke (2002), Pine \& Gilmore (1993), Lash \& Urry (2002)). The framework of a "New Economy" based on cultural values with labels such as Experience Economy or Dream Society has been launched during the last decades. We will discuss some of the major writings in order to define their usefulness for understanding an emerging "New Food Economy" with cultural production of added value as a common denominator. Firstly, the definition of New Economy in use here is reference to the increasing intertwinement of symbolic cultural messages and economic processes, the desired outcome of which is economic gain. The use of symbolic cultural messages is a key element in the New Economy, as it involves the responsibility for consumers to develop skills in 'reading' cultural values and, as Lash \& Urry (2002) and duGay \& Pryke (2002) point out, brings in references to the New Economy as being an 'economy of signs'. DuGay \& Pryke's argument also outlines that there are an increasing number of goods and services that can be regarded as 'cultural' goods. Their use of 'cultural' goods refers to the inscription of meanings and associations to elicit consumer desire for their purchase - exactly what our cooks are trying to achieve - but from this view it is unclear if food is part of the basket of 'cultural' goods in the New Economy. They further describe that:

There is a growing aestheticization or 'fashioning' of seemingly banal products whereby they are marketed to consumers in terms of particular clusters of meaning, often linked to 'lifestyles' and this is taken as an indication of the importance of 'culture' to the production and circulation of a multitude of goods and services (as quoted in duGay \& Prkye, 2002, p. 7)

The inclusion of 'banality' would seem to infer that food is indeed inclusive; as Jönsson (2005) outlines in his discussion of milk, he demonstrates an obvious connection in the New Economy due to rapid development pace and inclusion of cultural messages in added value products in the dairy counter. While the mention of rapid development would seem to indicate the there is something new happening with the 'fashioning' of meanings embedded in (banal) food products in the New Economy, Jönsson continues that this may not necessarily be the case. As he outlines, "the production of such "value-added products" can be seen as a part of a general conversion (to the New Economy), but it is suggested that it can just as well be that the economy is increasingly bent on trying to capture experiences that have always been conveyed via food" (2005). In other words, the meanings inscribed in value added food are an amplification of information that is already known, and communicated via experiences, bringing in an inclusion to the 'Experience Economy' as well. A concept discussed by Pine \& Gilmore in 1993, they outline the construction of experience 'spaces' as key in the eliciting of emotion for economic gain. In this world, no one sells mere commodities ... they sell 'lifestyles'. That the spaces Produc- 
ers develop to sell their products are in part to create emotion further embeds them in the experience economy.

It is here that I position small-scale Producers - within the New and Experience Economies, producing products inscribed with cultural values: but as will be shown, the inscriptions made utilise previously held cultural knowledge. The role of those who create cultural inscriptions is continued by Lash \& Urry:

This process, they argue has been accompanied by the increased influence of what are often termed the 'cultural intermediary occupations' of advertising, designing and marketing; those practitioners who play a pivotal role in articulating production with consumption by attempting to associate goods and services with particular cultural meanings and to address those values to prospective buyers... these signifying practices in doing business is evident not only in the production, design and marketing of goods and services, but also the internal life of organisations as well (as quoted in duGay \& Pryke, 2002, p. 7).

This further embeds the position of cooks as 'cultural intermediaries'. Another key supporting element of Lash \& Urry's description is the increased importance accorded to signifying practices that create symbolic value in the production of goods and services, such as those of small-scale Producers under investigation here. It also calls into account for the wider food industry to understand that it's not only the communication messages that are interpreted here: it is the reading of the entire production process.

Accordingly, an investigation of understood cultural values and production processes over time provides foundational information in understanding the context of value adding in the New Economy. Searching the historical roots of the emergence of late modern value added food production, Warren Belasco stress the importance of the radical counter cuisine against mainstream food ways that began to emerge from 1966. Some of the more important elements were:

- A consumerist component offered survivalist advice and suggested what to avoid, especially processed 'plastic' food.

- New ways to make food more fun - e.g. through the delight of improvisation, craftsmanship, ethnic and regional cooking.

- The organic paradigm, which posited a radically decentralised infrastructure consisting of communal farms, cooperative groceries, and hip restaurants (Belasco, 1989, p. 4).

While the countercuisine initially was interpreted as a threat by the major food companies, the ideas soon became the main inspiration source for product development. The wide range of rural, authentic, hand made, old-fashioned, ethnic and light products launched the last decades owe a lot to the counterculture of the 1960s and supports the use of this theory as still applicable in the food industry today.

Further support that these elements are still in demand today is an appreciation that the decentralised infrastructure Belasco refers also includes Farmers Markets, Farm Shops and 
specialist stores - all of which are preferred sales channels of Producers in this study. The emergence of the Farmers markets as an alternative food channel became evident during this cross over period between the second and third food regimes. The first Farmers Markets were reported in the US during the 1970's, with a slow expansion over the subsequent twenty to thirty years - however increasing at a faster rate in more recent years. The market in observation for this study has been in operation since 2000. As shown on the chart below, the number of operating Farmers Markets in the US grew by seventeen per cent to 7,175 from 2010 to 2011 alone.

\section{Number of Operating Farmers Markets, Total US}

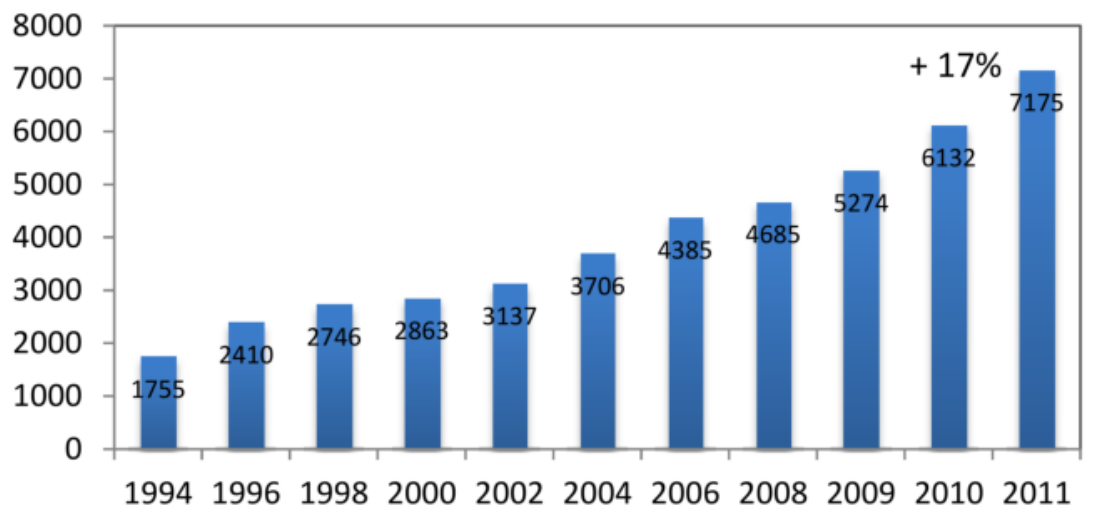

Chart 1. Number of Operating Farmers Markets, Total US Source: United States Department of Agriculture, 2011

Richard Wilk (2012), in his description of the contemporary food movement, also points to the growth of Farmers Markets, local food councils, regional food alliances, school food initiatives, community gardens and orchards, and popular interest in the quality of food over the past five years... and like Belasco, wonders if these will be exploited as a marketing opportunity or turned into an ideological foundation for change in the food landscape.

This counter also marked the emergence of the consumer as a voice of influence in the food industry, after the focus to internationalisation and mass industrialisation in the first and second regimes. A key point of Belasco's analysis is his argument that marketers who 'abused' the process turned this counter into mainstream belief. To what process does he refer? He describes the way in which marketers turned these beliefs into profitable products was by turning food messages to meet desired consumer lifestyle and identity values, and it was this focus to meeting consumer lifestyle needs that created their voice of influence. In order to communicate to identified values, marketers repositioned food added values. Belasco describes a deceptive 'picking and choosing' process where 'good' elements of products were chosen to anchor repositioning in lifestyle values, and the 'bad' elements were ignored or glossed over - for example, carbonated soft drink became 'low in fat' to embody consumer desire for a healthier lifestyle (Belasco, 1989, p.212). 
The success evident in relevant consumer re-positioning, demonstrated below with organic retail sales - even with potential drawbacks of its use, particularly when deception or excess 'glossing over' is involved - has lead to virtually an entire industry shift to how food products are communicated to consumers.

\section{U.S. retail sales of organic food products increase from 1997 to 2008}

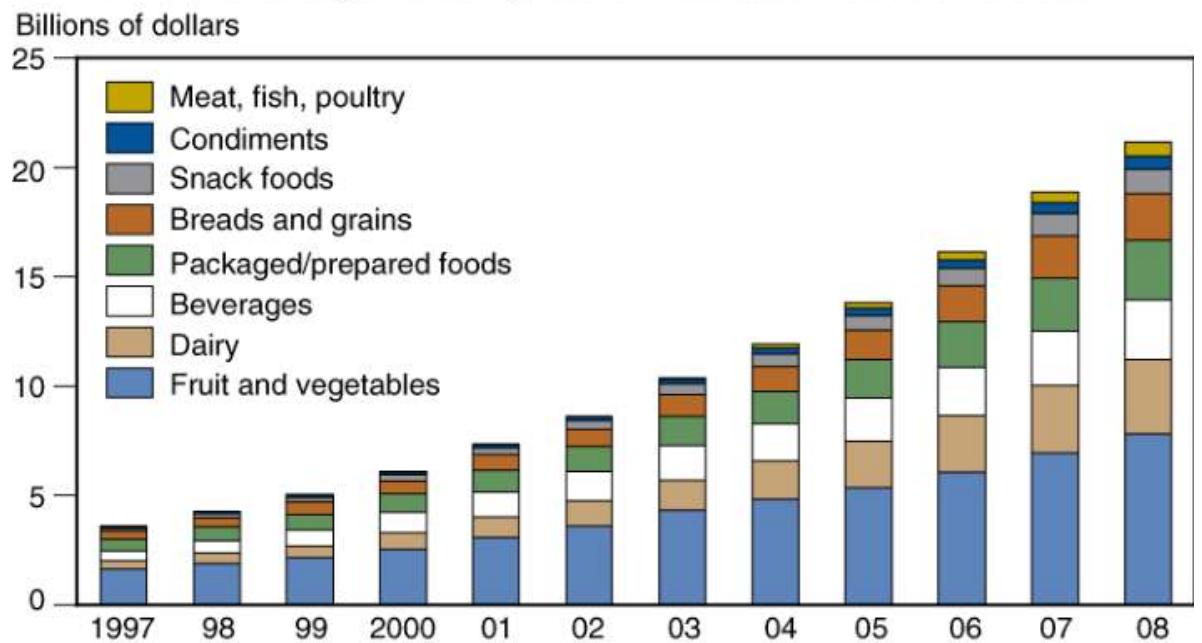

Chart 2. Retail Sales Growth of Organic Food Products. Source: Dimitri \& Oberholtzer $(2009$, p. 13)

Products and their messages began to transform from functional communication style into symbolic lifestyle and experience messages - and it is this process of how consumers read these messages that underpins Belasco's argument in how the counter became mainstream, for without the culturally held knowledge to 'read' the message conveyed, for instance, using a picture of a tractor on a green field is a farm, is completely lost.

It is the process of developing symbolic representation and cultural construction of small scale Farmers through their production and selling methods that allows a simple understanding and competitive advantage in a confusing food landscape. This occurrence is made all the more interesting in a wider food industry of careful, researched product positioning and communication from larger scale manufacturers: to achieve this, the small scale Producers in this study are unconsciously just doing what they do. 
I am a farmer's daughter, and my mother, she cooked jam and juice and all this that we also do, but she was never paid for it, but we are... and that is the difference between the $20^{\text {th }}$ and $21^{\text {st }}$ century! (Skåne Producer, November 2011).

\section{Method and materials}

For this investigation a specific empirical study involving small-scale value-added producers in the Skåne region of Sweden was undertaken. ${ }^{1}$ Taking an ethnographic research approach, observation and participant consumer observations were undertaken at a periodic Farmer's Market held in Malmo, Southern Sweden, over six Saturday mornings during 27 August 2011 to 15 October 2011. Ethnographic enquiry in this instance is a method to investigate value adding due to the focus on consumer / producer interactions and the evaluation of signs inscribed in products and material items used in display. It is also a relevant methodology to 'move the conversation forward' regarding value adding, as common industry methods such as quantitative surveys have apparently failed to provide underlying and unconscious motivations in their subjects of study. This particular market is advertised with an express requirement that all produce for sale there is made and sold by local Skåne smallscale farmers. As such it is a good market to begin investigation of producers and also analyse the material representation of space at the market, as each stall was under control of the individual producers themselves. Notes were taken directly after each of the six visits to the market (it is difficult to write while standing up in a crowd of people), in a nearby café, with a focus to the salient events from each visit to the market. Each visit on average lasted fortyfive minutes to one hour.

Each visit to the market had specific item to review. In week one, which was also the first market day of the market season, the organiser of the market was interviewed, and introductory contacts with all twenty one stall-holders present on that day. The attention on this day was drawn to the ways in which the organiser the perceived competitive advantage of the Farmer's Market, the type of consumers she believes shops at the market, expectations of the coming weeks' market sales and also the best way to market Producers' product to consumers, (particularly for newcomers to the market, of which there were two). The second week the investigation of the market were directed to the specific intention to review the material representation of space - display items outside the products themselves and signage that producers commonly use.

The third week, focus was to body language and behaviour between stallholder and consumer while tasting and/or buying products. Week four was focused to obvious advertising promotional or 'special' deals available at the market. Week five required another review of material representation (a repeat of week two), and the final week was spent looking for details missed on the previous weeks. 
Additional ethnographic observations were made during farm visits, and hour long depth interviews were also conducted with four producers during October and November 2011, in addition to an online questionnaire circulated to farmers in attendance at the market, of which fifteen responded. The online questionnaire, which participants were able to respond anonymously is a recognised departure from ethnographic methods, however was circulated primarily as a way of locating participants for deeper investigation.

However, the understanding of why certain questions were answered as they did in the questionnaire revealed again that qualitative methods uncovered much more about Producer value adding practices than straightforward quantitative line of questioning, and adds further support for the use of a cultural analysis approach in the articulation of meaning. All of the depth interviews were conducted with the use of an interview guide allowing to focus the majority of attention to the subtle emotions the became evident during discussions. What subjects created the most emotion? These subjects became focus for later analysis. In addition, web ethnography was also undertaken of Producers at market to understand their representations of self and product online, and was also taken into account during analysis and depth interview guide preparation as required.

Of the four depth interviews conducted, three were held on the site of farming production which usually also housed home, office and Farm Shop where their produce was sold. This gave an opportunity to view participants in the scene of their day-to-day lives, which often involved family.

The main field work was conducted at the Farmer's market in Malmö in the South of Sweden. As other Farmer's markets throughout the world, it was built around a specific regional provenance (in this case Skane, the most southern part of Sweden, which produces around $50 \%$ of the Swedish food production) the number of stalls selling produce that had been mediated and transformed in some way (such jams, smallgoods, rapeseed oils, breads, cheeses), and the stallholders were also the producers of the products that they sold.

Johnston \& Baumann (2010, p. 70) have tried to decode the elements of Authenticity that consumers demand in high-value food. They claim that geographic specificity, simplicity, personal connection, tradition, or 'ethnic' connections are the manin elements of authenticity. They report that from a consumer perspective, a 'good' authentic product does not need to have all these elements, perhaps one or two... but a really authentic product from a consumer perspective has elements of all five. This market communicated most, if not all of these elements.

While watching Producers carefully setting up their stalls to display their product in a way they deemed the most appealing, and engaged in passionate descriptions about the product they sold with consumers, it became obvious that there was a very close connection they made with their product. Their products were tended with almost maternal care. Jars were carefully and individually placed, labels facing forward... not too cluttered, each jar having a right to stand on it's own. Esteemed flavours stood centrally, close to where the stallholder could easily access for offering tastings and making serving recommendations. It was explained that this set up and staging was taken very seriously, with the utmost 'attention that 
must be paid to the small details in a display' - right down to the pattern on a table cloth used to conceal a rickety, aged wooden table. The care and thought placed into the display interestingly revealed a pattern of placing the stallholders themselves as co-stars and leads to the first Producer practice in adding value.

Observing the interaction between consumers and producers at the market, it became evident that exchanges were based not only on direct economic issues such a price. There was much more under discussion underway. Even though the elements of authenticitiy described by Johnston \& Baumann were found at the market, the elements as such does not give full credit to the practices involved. And they certainly do not answer the question why certain producers and products seem much more authentic than others, although they share the same elements.

The study of the actual practices of value making made some new themes emerge. They are summarized under four headings; Co-creation, The farmer myth, Art and Magic.

\subsection{Co-creation}

The online questionnaire circulated to locate participants for this research included a question that asked: 'of your current distribution channels, which do you prefer? Please select one from below'. The majority of respondents $(66.6 \%)$ indicated Farm Shop or Farmers Market.

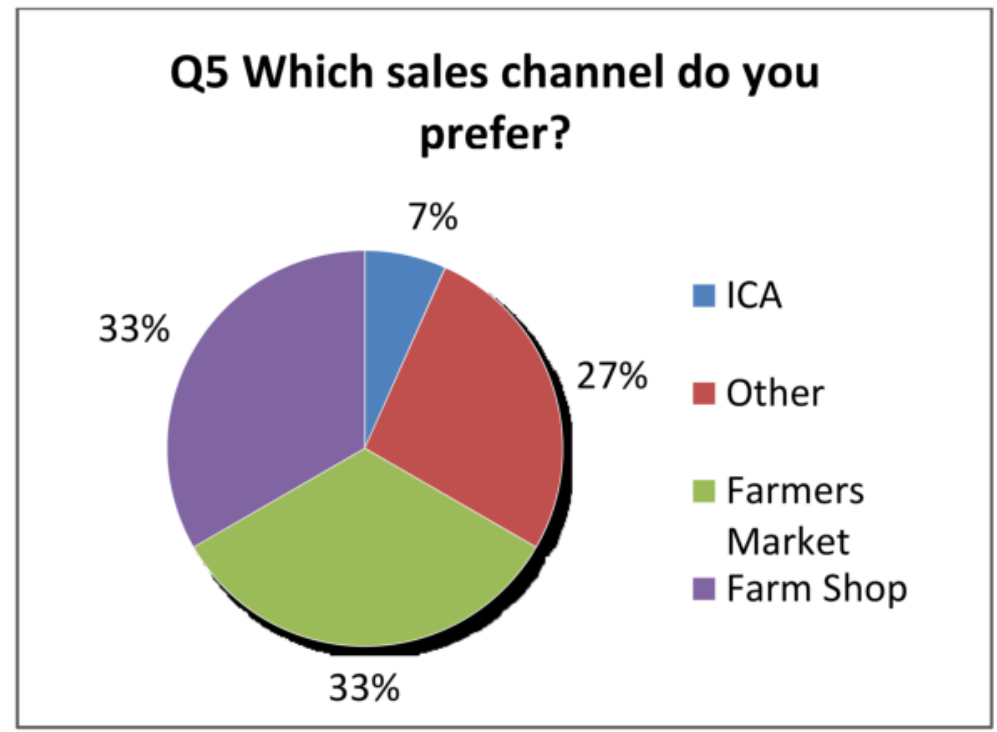

Chart 3. Preferred Sales Channel, Producers in Skåne, Sweden. Source: Online Questionnaire, August 2011. (Note: 'Other' is predominately 'Restaurants' ) 
This piece of information on its own is a little bit 'nice to know' as it fits with the preferred channels of the counter movement outlined previously. When asked about why Farmers Market or Farm Shop is preferred, most participants indicated it was personal selling and consumer contact that they like the most about these channels. There was a consensus that selling in this way was intensive work, but it was 'worth it' - there was significant return for labour. Which begs the question: What is it that they are getting in return? Is it purely economic gain?

Evident from the exchanges observed at the Farmer's market and discussed in later depth interviews indicated this return contained multiple components. A key component was one of education. Producers and consumers educate each other about the meaning infused in the food (consumers commonly rewarded the product for being hand-made), new ways of consumption and suggested occasions (try this with blue cheese, perfect for a summer party!) important in meeting the consumer and Producer need in identity building and class positioning through cultural capital. As Producers spoke about their product, they educated consumers about varieties of produce included in the food (i.e.; The tomato used is Roma, best suited for this type of relish), and also, importantly, Producers gained ideas for new product development through suggestions from consumers. The drawing of new products into the discussion may at first seem a little offensive, but later discussions with Producers revealed that this type of communication is invaluable information for new product generation and development, and has been credited with sparking ideas for product and also material displays of space. Two examples of this involved a recent award-winning product with the unusual inclusion of a savoury, exotic spice to a sweet condiment - tapping into an emergent consumer trend for food exoticism. The second example regarded the co-creation of one producer's use of the ubiquitous 'chalkboard' sign:

When I started, I wrote by hand (the signage) and I do not know how many times I bowed and curtsied for customers and apologised, how it was awful and all of that. And then a lady comes and she says to me like this: 'But, it is proof it is handmade'. Huh! (Laughs)... Sigh! It was, of course! (Skåne Food Producer, November 2011).

It was also revealed during depth interviews that disagreements with consumers may occur (usually regarding their 'confusion', or as one Producer referred 'blasé and spoilt', when talking of one discussion over the use of plastic wrapping around a herb plant, the consumer thought this meant it was not grown at site and objected to its use), however Producer position was always made in reference to their relation as the solution to confusion rather than the cause of it. It was also revealed that Producers rarely discuss new product ideas with other producers, as 'the market in small in Sweden - you have to learn to stand on your own', indicating that there are limits to the farming community in Skåne. Exceptions to this were evident, however only when a philosophical connection and strong friendship had been formed over a number of years.

These exchanges with consumers are very much a two-way communications process, and, to reference to Prahalad \& Ramasway, an exchange "between the firm (Producer) and the consumer (in) becoming the locus of value creation and value extraction" (2004, p. 6) and is 
an invitational act of co-creation. The co-creation is the centre of value extraction and knowledge for Producers to build their producer offer and the way they sell their product, and as such is held at a high level of importance.

While Prahalad \& Ramasway's (2004) investigation examples primarily involve larger corporations, such as car manufacturing giant General Motors - what stuck with the discourse with consumers was that small-scale Producers are routinely in a position that larger business pay large amounts of research money for... in direct contact with individual consumers who are eagerly sampling their products, freely offering feedback, sharing tips from other sources, with the added bonus that the consumer is speaking with a person that has a level of influence within the business structure to initiate change. Small-scale producers are very close to the consumer via their preferred distribution methods, and in a position where they can respond relatively quickly to changing consumer demand. However, as Prahalad \& Ramasway articulate, this is achieved not by only just 'showing up' at the Farmer's Market or opening a Farm Shop. To do so, Producers must invite feedback. Do they? If so, how?

Exploring the practices that Producers engage to begin the co-creation process at market started to tease out more information. The approach to addressing this question firstly lay not by observing Producers that appeared to be engaging in a co-creation with consumers, but by observing Producers that were not. There were two stalls at the market during fieldwork, both of which consistently had uncrowded stalls while the remainder of the market teemed with activity (one sold shiitake mushrooms, the other corn).

There were two common denominators between these stalls: 1 . Their product offer was not immediately apparent it was 'value added' and 2. Their stalls featured little to no elaboration in their stall displays - no or very limited signage, no extra items to add visual appeal, and symbolically represent a return to the farm / authenticity such as the previously mentioned flower arrangements or wooden crates. There was no elaboration in the space to communicate their values, which as discussed earlier, are important in the social construction of authenticity.

The absence of continuous consumer - producer dialogue at these stalls would seem to indicate that consumer feedback and discourse is in support of Prahalad \& Ramasaway's theory in that it is invitational. This occurrence implies that there is prerequisites involved the staging of experience in order to co-create with consumers. The invitation extended by a Producer must materially demonstrate their authenticity by the use of symbolically loaded material objects, and further offer an experience such as tasting plates before consumers will engage in discourse. It would also seem to indicate that non-value added products are perhaps not necessarily seen as something in which to discuss in greater detail than necessary to complete a financial transaction again bringing to mind LeviStrauss with his cooking as a mark of culture.

\subsection{The farmer myth}

The symbolic meaning communicated by the material display items in use is a key point here. As the symbolic loading in these items is culturally held, unconscious knowledge, further analysis is required. After all, the person that builds the displays first imagined it in their mind - perhaps they didn't realise how those images got there. The displays heavily 
utilise cues for 'authenticity', and for discussion of this I'll elaborate on what I am calling the Farmer 'myth' utilising Barthes.

One of Barthes "lasting contributions... was the identification and interpretation of certain 'mythologies' that he drew from everyday life in France" (as quoted in Atkins \& Bowler, 2001, p.6). Barthes utilises semiology as a tool to understand the basis for myth creation, and relates the expression of myths as inherent in food. As Barthes stated: "for who would claim in France that wine is only wine?" (1997, p.20) relating wine as a symbol of France and to the myth of what it means to be 'French'. Likewise, in the current food regime of counter-values to mass industrialisation, the myth of farming is utilised in small-scale food production to embody a 'return to the farm' in support of their authenticity.

The Producers are met with a challenge, though: this use of these 'return to farm' signs is not a unique in the food industry today, as Belasco previously outlined in discussion of the emergence of the food counter culture. Most of the items in use here to symbolise the return to farm can also be found represented on numerous food packaging, and in virtually every food distribution channel, including mass supermarkets and speciality stores. Items such as chalkboards, wooden crates, wicker baskets, striped awnings, are in common use in supermarkets and speciality stores around the world.

But what of our Producers in this, using the same material items, yet successfully inviting co-creation with consumers? With this proliferation of material displays in use in the market today, why are these displays not approached with cynicism, disbelief, or just plain dismissal? Here Baudrillard makes a contribution with the outline of two distinctive features of mythology to be drawn as relevant: "firstly the nostalgia for origins, and secondly the obsession with authenticity" (1996, p. 76). Baudrillard outlines that the obsession with authenticity is reflected with an obsession with certainty - specifically, certainty as to the origins, date, author and signature of a work, continuing:

The fascination of handicraft derives form having passed through the hands of someone the markers of whose labour are still inscribed thereupon: we are fascinated by what has been created, and is therefore unique, because that moment cannot be reproduced (1996, p. 76).

In co-creation the feature of certainty in myth here is a distinct element in invitation: the certainty that in a confusing food landscape and the new economy of signs, where authenticity is hinted at almost every turn, that the Producers are farmers. There is certainty created in regards to the origins of the food, as the author and signature to the work, often accompanied by undeniable physical presence. What could be more certain than that? This invitational certainty is in direct contrast to Prahalad \& Ramasway's theory where they propose that 'trust' (or certainty) is an outcome of co-creation (2004, p. 13). Here we propose it is a central element in use at the beginning of the co-creation process. It's the certainty that Producers can truthfully and safely take consumers from myth and into reality. 
In the next section, the displays used at the Farmer's Market is contrasted to the spaces constructed at Farm Shops - with the consumer on the farm, the invitational space to co-create becomes something else entirely.

\subsection{Art}

When discussing five-year plans, most Producers indicated a desire to increase business through their on-site Farm Shops - all of the depth interviewees had a Farm Shop, and thirteen of the fifteen respondents to the online questionnaire did also. These shops are under their full control, and thus ideal to explore the more permanent environment (compared to the Farmers Market) in which they have constructed to sell their product. All the producers referred in depth interviews to a desire to elicit positive emotion from consumers from their Farm Shops, something they felt that large supermarkets could not $\mathrm{do}^{2}$.

One Producer spoke about their delight with their shop layout creating happiness, astonishment and surprise emotional reactions from consumers:

\footnotetext{
In my farm shop I don't stock these types of everyday products (sold at ICA, a large supermarket chain in Sweden). No, what I have here has nothing to do with everyday commerce. There is no milk... I do not have those types of products, this is really speciality items... I really take it to myself, how I have been thinking when I planned the store. "What should it look like in the shop to make it inviting to the customer, inviting to enter and to have a look?" Often I say... (Pauses: body language changes, pulling away a little bit - it's like a self reprimand for becoming a little too pleased with oneself, quickly decides on an acceptable rephrase, leans forward again) ...the customers usually stand in the door and say. "OOOOH what a lot of, AHHHH how nice!" Then they are of course happy, I think! (Laughing). Yes indeed! Most of them are perhaps a little astonished and surprised, because they don't expect anything more. (Skåne Food Producer, November 2011).
}

Arguably this is an effort to create a unique positioning and distance to the dominant food sales channel today (supermarkets), however the exclusion of what is perceived to be everyday products raises some important questions regarding the 'specialness' infused their products and reveals beliefs about the work they do. Why is an everyday food item such as milk not considered 'special', particularly when considering that a number of products for sale in this store could be considered as 'everyday' use items such as jams and mustards? Consideration of the space implies an effort to raise their product above the everyday and into a form of art, and in doing reveals Producer cultural capital and class aspirations.

To communicate their perception to the specialness, non-everyday, uniqueness of their products, Producers reveal a tacit, cultural understanding to their construction of space, and have turned their Farm Shops into spaces resembling Art Galleries. The Producer quoted earlier in this chapter created a large space, beautiful to look at, with a significant amount of

2 In the online questionnaire, Producers were asked to nominate the emotion they felt consumers experienced in different sales channels. $80 \%$ of participants believe customers feel 'negative' emotions such as neutral, bored or confused in Supermarkets. 
non-food items, and set up in a maze of stalls to encourage exploration and discovery. Another Producer housed several buildings, one of which featured a café with soaring cathedral ceilings, artwork on the walls, and with their produce barely visible in - again - a beautifully constructed space. The farm shop was located in the same building where the produce was 'cooked', separate to the main house that was a short distance away, however all cooking space was off limits and invisible to regular custom in the shop, as were all of the cooking spaces in the farm shops visited as part of this study.

In guided tours with Producers at their farm shops, there was always a respectable distance kept from the Product in store, to allow the viewer to take the entire scene in. The lighting scheme shined directly on produce, to illuminate its form. The display of goods was uncluttered, so as not to catch a wandering eye's attention from the main event. Discussions commenced about why the products on display were chosen with slightly hushed tones, even if we were the only people in the store. These actions struck as being very similar to behaviour that would be found in art galleries - here, a discussion was ongoing with an Artist. An artist creates. What are these spaces creating?

The construction of these spaces to resemble art galleries attracts the use of the term 'Experience Economy' as introduced in theoretical framework to elaborate and further embeds Producers as active participants in the Experience Economy. The art gallery spaces are carefully staged for consumption and construction - consumption of the producer, consumption of myth, consumption of art... and hopefully for our Producers, what follows is the consumption of authentic 'special' food products.

Tom O'Dell \& Peter Billing (2010) outline a useful interpretation regarding spaces that are staged for consumption using a theoretical framework that combines the conceptual tools of Arjun Appadurai's (1996) 'scapes' and Henri Lefebvre's (1991) production of space. Herein they have developed an understanding that spaces where experiences are manufactured for consumption can be interpreted as "places in which the global and the local are entwined and where power relations played out, political interests are material interests are materialised, cultural identities are contested and dreams are redefined" (O'Dell \& Billing, 2010, p.18). The building of producer's identity through practice is a key function of the space created. The environment feels very much staged for artistic expression and exploration... a space has been created that Pine \& Gilmore (1993) could interpret as a carefully staged production to create experiences such as those available at Disney or the Ritz Carlton.

A main criticism of Pine \& Gilmore's description of the 'Experience Economy' is that the spaces as provided as examples (such as Disneyland and the Ritz Carlton) are created with the assumption of a passive receptivity - consumers have no hand in creating the space and limited opportunity to personally shape it. However, as is known from the previous research finding, co-creation is a key element to Producer practices and the impact of consumer feedback on the construction of this space cannot be underestimated - regardless if the Producer is conscious of this or not. The inclusion of art indicates a desire for the accumulation of cultural capital in identity construction, not only for Producers, but for their consumers, also. The construction of this space seeks to confirm Producer position within upper 'cultural capital' class, and the investment of time, money and plan- 
ning into the ongoing operation of their galleries demonstrates a long-term desire to retain this class positioning.

\subsection{Magic}

Magic, the art of influencing through supernatural means, could infer secret, hidden and disappeared acts in production practices without clarification of its use. Here, magic is described and applied using two references from the social sciences - Sir James George Frazer (Social Anthropology) and Marcel Mauss (Sociology).

In 'The Golden Bough' first published in 1890, Frazer notes magic generally falls into two categories: the Law of Similarities and the Law of Contact or contagious magic. The former applies to the belief that like produces like - an example used was "the then current belief in among peasants in the Balkans that swallowing gold could relieve the symptoms of jaundice" (Barnard \& Spencer, 1996, p. 341). The Law of Contact or contagious magic was causal idea of things that had once been in contact continued to influence on each other at a distance.

In describing themselves in their products, Producers emphasise 'them' as integral to the product offer. This introduces a belief that they hold continued influence in and over their product before, during and after consumer purchase, to continue the communication of their authenticity, thus asserting their influence at a distance via magical means. In discussions with Producers, the appeared to be little separation between Producers and their products ... the way their products were referred was often in the same way that you would refer a person. The extension of themselves as represented in their products created a desire for their products to be treated as how they would personally like to be treated. For example, it encouraged a slight concern about selling in delicatessens where there is a perception consumers are particularly discerning and demanding, which means the chance of product rejection (and thus, themselves) is higher. Producers also held a strong resistance to sell in supermarkets where their product could become the 'little' with scant consumer attention (a bit like going to a crowded party and standing alone in the corner), or face the potential of having their product abused in store by careless staff.

The Contagious Magic in use by Producers is a practice to infuse a competitive advantage they believe to be what no one else has into their products: themselves. Producers are the magicians in their kitchen, infusing themselves in their products. Two quotes from research summarise this belief in infusion of self very well. One Producer mentioned that their soul must be in the product:

\footnotetext{
I have nothing to sell if there is no soul in my product... then I find it difficult to justify why the customer should buy my (product), then he can buy another, because what's unique in mine is that $I$ cultivate it. It should be something that no one else has. (Skåne Food Producer, November 2011).
} 
While another in responding to a question asked in the online questionnaire: 'If your favourite product could talk, what would it say to consumers?' The response neatly stating: 'I am special, unique and wonderful. And you?'

Additional theory to view producer practices using Magic is provided by Mauss in 'A General Theory of Magic' (2001), which is that of a social phenomenon containing belief and rites.There must be a magician to produce an act of magic, and an audience to believe in this act. Rites are developed to enact and perform the magic. Magic is not a one-time occurrence; magical performances are repeated patterns of behaviour and when at it's most successful, refer to "those things that society as a whole considers magical" (Mauss, 2001, p. 22). As O'Dell (2010) describes, the inclusion of belief in this theory provides 'special problems' that will be revealed as particular relevant for this discussion:

\footnotetext{
Magic is an institution only in the most weak sense, it is a kind of totality of actions and beliefs, poorly defined, poorly organised even as far as those who practice it... It's existence necessitated two different forms of belief that he (Mauss) called a 'will to believe' and 'actual belief' (p. 57)
}

The problem being, for acts of magic (or influence at distance) to be not seen as trickery, they require collective belief by all actors involved, with each actor having a role to play. The magician in this act is the Producers and it is here where belief does exist - but it is not without tension. Present and seemingly unwelcome is a level of uncertainty about their own skill and knowledge in their practice, that in conversation betrayed an oscillation between a 'will to believe' and 'actual belief'. This tension was managed by the development of magical rites, and as far as they could possibly manage, a self-imposed 'nocheating' policy on these rites.

These rites specifically managed the symbolic values they use to describe their products as authentic - themselves in the product made it hand-made, home-made, crafted. The translation to practice is rather literal: to be home made, the production practice must be either in their home or in a nearby building as part of their faming complex, never in a removed and distant facility. To be hand made, their own hand must be involved in making the product, and they must perceive a level of craftsmanship involved in the transformational cooking process. One Producer described the importance of seeing and inspecting each individual raw main ingredient with his or her own eyes. Another Producer describes the importance of the cook (themselves) to be directly involved in the cooking, cooking in low batch volumes and never on a stove that could be considered 'industrial': 
...And also describes readying themselves psychologically as to not infuse the products with stress, which might negatively taint the flavour:

It is an experience, every day, every batch that is made; you do not always get the same batch or the next batch exactly the same with the same products. It depends on your peace of mind, on how much you put in your measuring cup. It has to do with... well, if you are under stress... all those things matter (to the final product). (Skåne Food Producer, November 2011).

However, these assertions were made at the same time limitations and exceptions were made obvious, and showed clearly the edges between a 'will to believe', 'actual belief' and deceit. It and also showed differences of opinion and poor definition where these edges actually lay between the Producers involved in this study - there was no common approach. Individuals had determined what fit with their magical act. For example, it's understandably difficult to grow all of the required raw ingredients for a product on the one farm, so while it is important that they farmed the 'star' ingredient in their products, it appears that consideration to all origins of the ingredients in use are not considered as heavily - one Producer mentioned popping into the local ICA store whenever an ingredient was needed, and had never checked the provenance of the product bought there for that purpose; while another mentioned checking provenance of all the ingredients they use. Another mentioned the recipe for one product was something they looked up on the Internet, hardly conjuring images of crafted, while a different Producer claimed that all recipes they used were the result of experimentation in their home kitchen. Another mentioned that they had employed Polish workers to pick their raw ingredients as a cost saving, and wondered if this were doing the 'right thing' in terms of authenticity. In this instance they looked but did not find an exception to the rules of hand and home made, as they were selecting the produce to cook from the yields themselves - but this Producer conveyed feelings of unease and insecurity about their decision. It appeared to be a compromise in their hand made claims.

As these edges are indistinct, blurry, and left to the Producers themselves to navigate, the inclusion of magic rites to infuse themselves in their products brings a host of anxieties in addition to an immense sense of pride. It has also turned their attention to and creates a high level of reliance on consumer approval. The consumer is seen as the ultimate judge of magical efforts, and also aligns with Mauss's outline of magic as an act that "society considers magical" (2001, p. 23) - everybody has to believe in the act of magic to be true. In this case, consumers are representations of society. When Producers are asked why they engaged in the business that they do, this is commonly the first aspect mentioned - it's a checking of consumer belief in their magic, expressed in a desire to please: 
'I do this to delight my clients'

'I can't sell anything unless the customer is satisfied directly'

The importance of bringing consumer satisfaction - and by extension, belief - through their produce underpins and adds meaning and reinforces their belief in their rites of magic. Feedback from consumers is actively gained from Producers when possible, and it is this information that is actively sought and helps guide further practices, as discussed 'Co-Creation and Certainty of Myth' finding.

The execution of these magical rites also brings small-scale food production to more closely resemble a creative processes (such as art or fashion) rather than a production process (such as Fordist production methods), and again brings food production to in closer alignment within the New Economy. In order to execute their magical rites, Producers must manage themselves, their lives and their work in a way that optimises their creativity and mood to enact their magical acts, which blurs the line between 'work' and 'play'. Here, Löfgren and Willim (2005) refer to the use of magic as central to emergent people and self-management methods in the New Economy, where the introduction of 'fun' has become a central concern.

This management of self is referred to as 'reflexivity' by Lash and Urry (2002) and described by McRobbie (2002) "as a form of self disciplining where subjects... are increasingly called upon to inspect themselves and their practices, in the absence of structures of support... reflexivity marks the space of self responsibility, self blame" (p. 522). Producers are highly cognizant in the requirement for individual responsibility in their rites, as I was informed 'you are held accountable for what you do'. Giddens' and Becks description of the concept as undertaking self monitoring activities' (McRobbie 2002, p. 522), is relevant in describing this accountability here and is further articulated by Lash and Urry:

\footnotetext{
Social agents are increasingly 'set free' from heteronomous control or monitoring of social structures in order to be self-monitoring or self-reflexive. This accelerating individualisation process is a process in which agency is set free from structure; a process which, further, it is structural change itself in modernisation that so to speak forces agency to take on powers that heretofore lay in social structures themselves. Hence for example structural change in the economy forces individuals to be freed from the structural rigidity of the Fordist labour process. That is, it is increasingly a pre-requisite... that the labour force becomes increasingly self-monitoring as well as develops an even greater reflexivity with respect to the rules and resources of the workplace" $(2002$, p. 5)
}

In this instance, the use of magic to add symbolic value of Authenticity in production methods has transferred Producer association away from the Fordist economic labour process, but embedded them more closely with the counter-structure that has developed in resist- 
ance to it within the New Food Economy. Furthermore, their intense self-monitoring has also developed skills of greater reflexivity with respect to the rules of their workplace that extends across their day to day lives, and creates a unique set of challenges inherent in operating in this way, which is discussed in the Research Finding Summary. As McRobbie describes the fashion industry in London (2002), this may mean holding down additional jobs in order to make ends meet - one Producer interviewed shovels snow in winter.

\section{Conclusions}

\subsection{Summary of findings}

In this article, new knowledge regarding the value adding practices to inscribe authenticity in food products is provided. The perspective from small scale farming Producers was taken; where co-creation, myth, art and magic are key practices utilised to value add products with authenticity.

Value adding is a common practice in the food industry, and is increasingly undertaken by inscribing lifestyle and cultural capital messages in food such as health, knowledge and class position, often by claiming some sort of "authenticity". The theoretical understanding in thesis outlined that authenticity is a social construction, and taking the view from Producers in this study, to be characterised with references to handmade, homemade and crafted messages inscribed into their products. These messages are understood via deconstruction of cultural codes. An example of this was demonstrated by the cultural perception of 'farming' to constitute a myth market that the food industry has utilised heavily in marketing communication messages. However, it was the deceptive use of communication messages by large-scale food companies that created consumer uncertainty to the real origins and production processes of mass-produced food, and opened small-scale production an opportunity to provide myth certainty to consumers with their products.

To value add their concept of 'authenticity' to products, rites of magic, co-creation, delivery of certain myth, and development of art spaces are undertaken. These practices differentiate and have been developed in counter to the dominant food system in order to create competitive advantage. In doing, Producers reveal culturally constructed beliefs about their relationship to their product, understanding of symbolic meanings in representation of space and their desired identity via cultural capital. It also reveals ignorance to the underlying cultural structure and history of food that has lead to their position in the food industry today.

As pointed out in the application of theory from the New Economy, the entire production process is increasingly taken into account when reading food messages, and it is here that small-scale production finds competitive advantage in the marketplace. However, Producers' lack of knowledge about how and why they came to a position of prominence has created uncertainty about their conduct now and into the future. To combat this, Producers have created magical rites and a high level of self-reflexivity in regards to their practices of authenticity, and a heavy reliance on co-creation with their consumers to develop their prod- 
uct range and material representation of space. The design of this space creates a sense of certainty for consumers that they were engaged with farmers and one of its functions is to create an invitational space for discourse. However, in creating spaces and products that the consumer demanded, Producers merely replicate current marketplace dynamics and base their business information only on what information their consumers can tell them - paradoxically, they attempt to surprise consumers with information that the consumers themselves revealed to them. It is here that a key advantage of Cultural Analysis is shown. With a wide theoretical and historical view, the food industry is outlined and underlying motivations and desires that neither consumers nor producers can articulate is articulated.

This article found that, as Producers and cultural mediators, Producers' own search for identity and meaning is inscribed in their products. In order to invoke the Law of Contact or contagious magic and influence their products at distance, they transform and value add their products by becoming magicians and undertaking rites of magic in their kitchens. These rites, while infusing their products with the desired handmade, homemade and crafted values associated with authenticity has created limitations to production methods, and also highlights the thin line that can exist between magic and deception. As individuals possessing cultural capital in the form of knowledge, Producers acknowledge and inscribe this power and transform what cannot be reproduced into their products: themselves. In paying very close attention to consumers, Producers have tacitly understood that their products represent a desire for cultural capital and class position, and have in response turned their farm shops into unique, non-everyday, special spaces that resemble art galleries. In doing, they transform themselves from cooks to artists, bring food closer to the Experience Economy, and also reveal and entrench their own understanding of 'culture' as high art; as opposed to the everyday. These actions also force a re-consideration of what business these Producers are actually in: these practices point towards a closer alignment to the service and artistic industries than to food.

Regardless, the belief in art, myth and themselves as value added determinants of authenticity has created practices that restrict income flow, with some Producers living on the edge economically. It also potentially creates risk in their business model should their product offer fall out of consumer favour as mysteriously (to them) as it fell in.

\subsection{Conclusions with applications and suggestions for future research}

The knowledge of the value-adding practices co-creation, farmer's myth, art and magic that small-scale producers use have several applications for food producers.

Firstly, it calls for a view of where business involvement actually lies, and why. In this example, small-scale Producers have combined elements of food and artistic industries as an expression of cultural capital for themselves and their consumers. The 'blurring' of industry edges in the New Economy is in itself not necessarily a brand new phenomenon in the food industry as Jönsson (2012) has outlined in 'The Gastronomic Revolution'. However, in this context it is evolving the question of why Producers are engaged in the business that they are, where more inspiration for application can be found. As Simon Sinek, cultural anthropologist and management and leadership author proposes in 'Start with Why' (2009), inspired 
leaders such as Steve Jobs, Martin Luther King, Orville Wright looked for their why in places based in altruism, common good and social betterment (which he suggests is another construction of authenticity), which in turn motivated and inspired others, and in doing turned their ideas into social movements. In other words, their why is the basis for construction of consumer desire. Sinek suggests that it is the articulation of why as the reason that consumers ultimately buy products or services. A further description in Sinek's book is in support of a key message in this article - that consumers will be unable to tell you what this why is. There may be some concerns regarding the why Producers in this study have employed, but it is currently a compelling and motivating proposition for them nonetheless.

A less individualistic, more collective and cooperative approach within the food industry, to educate and empower themselves and consumers, develop sustainable, kind and ethical business practices, and authentically communicate about how their food is really made could be a more compelling and sustainable why than what is currently employed. However, the thrust of this application remains for the wider food industry: using a cultural analytical approach, define what industries your business is involved and describe why it's important.

Additionally, it is the certainty that Producers can create through their value adding practices that constitutes part of their competitive advantage. The wider food industry, and mass production companies in particular, have heavily utilised and communicated the 'return to the farm' and 'farmer' myth. In so doing, they have shown just how powerful mythology is in our culture and how easily it can be communicated in marketing messages. Unfortunately, these messages in past use were often concealing large-scale production methods and laboratories that bear little resemblance to what is commonly perceived as a farm (or farmer). As this concealment was exposed over the years consumer distrust and cynicism crept in. What Producers are able to do in this climate is remain present in their farmhouse kitchens, and their Farm Shops, as consumers to come to them, and in doing, start to create a new view for consumers to build their perceptions regarding the myth of farming. The certainty that is created, and ability to begin changing the myth points to an opportunity not only for small-scale Producers to start using a heavier hand for the evolution of this myth, but for the wider food industry in developing certainty in myth-based marketing claims - by initially providing increasing transparency to business practices and building trust.

This knowledge also illustrates the magic in infusing authenticity - where a key element is the audience belief in the magical act. To develop rites without an audience means there is no magic; and conversely if you have an audience and there is no belief in these rites, again there is also no magic. There exists a thin line between magic and deceit. Magic is alike to authenticity in this regard: all actors involved have to believe it to be true. It is also a key element that provides competitive advantage, and Producers have selected a positioning that cannot be replicated: themselves. The authenticity in this study is predominately the Producers themselves; they have magically infused their sense of self as unique representations in homemade, hand-made and crafted production methods as part of their product offer. Which leads to ask the question to the wider food industry: What does authenticity mean to your business? Is it believable? Can it be replicated? 
A warning arrives in the form of the risk involved when an over-reliance on consumer feedback is evident in the production of practice. Some research methods, such as quantitative surveys, will merely reinforce current modes of behaviour and reveal only what lies at the surface, arguably providing a perfect template for continuation of business as it is today. This article illustrates that consumer feedback can be too much of a good thing if taken out of a wider cultural context. To build business with a large reliance on this practice is problematic - as mentioned in the Introduction, one cannot simply walk up to a consumer and ask them why they like a certain food product. They can't tell you. Co-creation discussions with consumers reveal more about the widespread consumer ignorance regarding the food industry rather than revealing how they could be surprised and astonished. There is nothing game changing about approaching a consumer in this way - it doesn't challenge the status quo, and will serve only to reinforce what already is. How can one be surprised if they can articulate what constitutes a surprise? A deeper and wider view provided through methods such as Cultural analysis theory and ethnology as a method will reveal culturally unconscious held beliefs, the structures that surround society that influence behaviour and uncover what the underlying motivations really are in value making and value adding.

Future research recommendations pay attention to assisting the development of knowledge of practices identified in this thesis, and in doing proposes a greater involvement and collaboration of actors across the food industry. The examination of value adding by small-scale food Producers in the New and Experience Economies is a relatively new area of study within the social sciences and warrants further attention.

Continuing the development of knowledge in regards to co-creation, a point of interest is made with reference to Douglas Holt (2004). Like Prahalad \& Ramasaway, his approach is positioned at the crossroad of marketing, brand management and cultural studies, and in his publication 'How Brands Become Icons' invokes the use of co-creation (what he terms as 'co-authoring') and mythology as a key to success in branding strategy. However he does not refer to the element of certainty or trust in myth. It appears to be a given fact that this commonly held cultural knowledge can and will be used by larger corporations in their branding and communication strategies, and begs the future study within these cross disciplines from a cultural analysis perspective as to the importance of certainty (or trust) as required before a marketing or communication messages is developed, particularly when mythology is in use.

The value shown in Cultural Analysis in this thesis is applicable not only to small-scale Producers in Skåne, Sweden, but other actors in the food chain as well. There is opportunity for mutual involvement and collaboration to the adding of values in food with a greater focus to education and involvement in the construction of consumer desire.

The inclusion of experience and art to food also indicates a need to more fully understand these complementary culture-production industries in this context. To facilitate this discussion, it is further recommended that Producers push past their currently defined limits of their community and involve with industry bodies such as the Skåne Food Innovation Network in their provision of opportunities for collaboration through networks and connections. Education forums with a Cultural Analysis perspective regarding value adding will 
help assist those in the manufacturing and production of consumer goods in the food industry understand their position and role as cultural mediators.

In closing, the role of small-scale food Producers is one that can be promoted with their collaboration, and in doing, can help build understanding that they do have a unique position and practices within the food industry. This will provide small-scale Producers with the confidence to further evolve their practices for greater economic return and business stability in the longer term as consumer demands in the food industry continue to evolve.

\section{Author details}

Rebecca Dare, Håkan Jönsson and Hans Knutsson

Lund University, Sweden

\section{References}

[1] Adams, C (1990). The sexual politics of meat: a feminist vegetarian critical theory. New York, Continuum Publishing.

[2] Atkins, P \& Bowler, I (2001). Food in Society. Oxford University Press.

[3] Appadurai, A (1986). The Social Life of Things. Cambridge University Press.

[4] Ashley, B et al, (2004). Food and Cultural Studies. Routledge.

[5] Barnard, A \& Spencer, J (1996). Encyclopaedia of Social and Cultural Anthropology. Routledge.

[6] Barthes, R (1997). Toward a Psychology of Contemporary Food Consumption. In Counhihan, C \& van Esterik, P (1997). Food and Culture: A reader. Routledge.

[7] Barthes, R (1967). Elements of semiology. London: Cape.

[8] Baudrillard, J (1996). The system of objects. London: Verso.

[9] Beck, U. (1992). Risk Society: Towards a New Modernity. London: Sage.

[10] Belasco, W (1989). Appetite for Change: How the Counter Culture Took on the Food Industry. New York: Pantheon.

[11] Belasco, W \& Scranton, P (2002). Food Nations: Selling Taste in Consumer Societies. Routledge.

[12] Bourdieu, P (1984). Distinction: a social critique of the judgement of taste. London: Routledge. 
[13] Connor, J \& Sheik, W. (1997). Food Processing: An Industrial Powerhouse in transition. New York, Wiley.

[14] De Certeau, M; Giard, L \& Mayol. P. (1998). The Practice of Everyday Life: Volume 2 living and cooking. Translated by Tomasik, T. University of California Press.

[15] Dimitri, C \& Oberholtzer, L (2009). Marketing U.S.

Organic Foods:

Recent Trends From Farms to Consumers. ERR-58 United States Department of Agriculture

[16] Douglas, M (1996). Thought Styles. London: Sage.

[17] Douglas, M (1982). Food as a system of Communication in Idem: in the active voice, London, Routeledge, 81-118.

[18] DuGay, P \& Pryke. P (2002). Cultural Economy. Sage.

[19] Ekelund, L; Fernqvist, F \& Tjärnemo, H. (2007). Consumer preferences for domestic and organically labelled vegetables in Sweden. In Food Economics Acta Agricult Scand C, 2007; 4: 229-236, Taylor and Francis.

[20] Euromonitor (2009). Retrieved at: http://www.euromonitor.com/packagedfood-2010-part-2-global-market-opportunities/report

[21] Frazer, J.G (1995). The Golden Bough. Wordsworth Editions Ltd.

[22] Friedmann, H., \& McMichael, P. (1989). Agriculture and the state system. Sociologia Ruralis 29(2): 93-117.

[23] Giddens, A (1991). Modernity and Self-Identity. Self and Society in the Late Modern Age. Cambridge: Polity.

[24] Goody, J (1982). Cooking, Cuisine and Class: a study in comparative sociology. Cambridge University Press.

[25] Hamrick, K; Andrews, M; Guthrie, J; Hopkins, D; \& McClelland, K. (2011). How Much Time Do Americans Spend on Food? EIB-86 United States Department of Agriculture, Economic Research Service

[26] Holt, D (2004). How Brands Become Icons: The principles of cultural branding. Harvard Business Press.

[27] Identity Advertising (2007), 'Final Coca Cola Plans Book', Retrieved at: http:// www.scribd.com/Sportzchick2287/d/2473813-Final-CocaCola-Plans-Book

[28] Innova Market Insights (2011). 'Top 10 Trends for 2012 and Beyond'. Retrieved at: http://www.foodandbeverage-network.com/blog/food_innovation?category $=6$

[29] Jönsson, H (2012). Den Gastronomiska Revolutionen. Stockholm: Carlsson Bokförlag. 
[30] Jönsson, H (2005). A Land of Milk and Honey: The Dairy Counter in an Economy of Added Values. In Magic, Culture and the New Economy. Edited by Löfgren, O \& Willim, R. Berg.

[31] Johnston, J \& Baumann, S (2010). Foodies: Democracy and Distinction in the Gourmet Landscape. Routledge.

[32] Lash, S \& Urry, J (2002). Economies of Signs and Space. Sage.

[33] Le Heron, R (1993). Globalised Agriculture, Political Choice. Oxford: Pergamon Press.

[34] Levi Strauss, C (1994). The raw and the cooked. Pimlico.

[35] Lupton, D (1996). Food, the body and the Self. London: Sage.

[36] Mc Robbie, A (2002). Clubs to Companies: Notes on the decline of Political Culture in Speeded Up Creative Worlds. In Cultural Studies, 16(4), 516-531.

[37] Mauss, M, (2001). Mauss: A General Theory of Magic. London: Routledge

[38] Mennell, S., Murcott, A. \& van Otterloo, A.H (1992). The sociology of Food: eating, diet and culture. London: Sage.

[39] Mintel, (2012). Retrieved at: http://www.gnpd.com/sinatra/gnpd/frontpage/? _cc=1\&utm_source=foodanddrink.mintel.com\&utm_medium=menu

[40] O'Dell, T (2010). Spas: The Cultural Economy of Hospitality, Magic and the Senses. Nordic Academic Press.

[41] O’Dell, T \& Billing, P (2010). Experiencescapes: Tourism, Culture, and Economy. Copenhagen Business School Press.

[42] Peteraf, M.A. and Barney, J. (2003), Unraveling The Resource-Based Tangle, Managerial and decision economics, 24, pp. 309-323.

[43] Peterson, R (1997). The Rise and Fall of Highbrow Snobbery as a Status Marker. In Poetics: Journal of Empirical Research on Culture, the Media and the Arts. 25: 75 - 92.

[44] Pine, J \& Gilmore, G (1993). Welcome to the Experience Economy. Harvard University Press.

[45] Prahalad, C.K \& Ramaswamy, V (2004). Co-creation experiences: the Next Practice in Value Creation. Journal of Interactive Marketing 18(3), 5-14.

[46] Reed-Danahay, D (2005). Locating Bourdieu. Indiana University Press: Bloomington and Indianapolis.

[47] Sinek, S (2009). It all starts with why: How great leaders inspire everyone to take action. Penguin, London.

[48] United States Department of Agriculture (2011). 7,175 Ways to Know Your Farmer, Know Your Food: Visit a Farmers Market. Agriculture Deputy Secretary Kathleen 
Merrigan. Retrieved at: http://blogs.usda.gov/2011/08/05/7175-ways-to-know-yourfarmer-know-your-food-visit-a-farmers-market/

[49] United States Department of Commerce (2008). Industry Report Food Manufacturing NAICS 311. Retrieved at: http://www.trade.gov/td/ocg/report08_processedfoods.pdf, pp 1- 13.

[50] Warde, A (1997). Consumption, Food and Taste: culinary antinomies and commodity culture. London, Sage.

[51] Wilk, R (2012). Lecture, Lund University, Sweden. 
